\title{
Article \\ Crack Forms Sensitivity-Based Prediction on Subsurface Cracks Depth in Ultrasonic-Vibration-Assisted Grinding of Optical Glasses
}

\author{
Peiyi Zhao, Lei Zhang and Xianli Liu *
}

check for updates

Citation: Zhao, P.; Zhang, L.; Liu, X. Crack Forms Sensitivity-Based Prediction on Subsurface Cracks Depth in Ultrasonic-VibrationAssisted Grinding of Optical Glasses. Appl. Sci. 2021, 11, 7553. https:// doi.org/10.3390/app11167553

Academic Editor: José A.F.O. Correia

Received: 9 July 2021

Accepted: 11 August 2021

Published: 17 August 2021

Publisher's Note: MDPI stays neutral with regard to jurisdictional claims in published maps and institutional affiliations.

Copyright: (c) 2021 by the authors. Licensee MDPI, Basel, Switzerland. This article is an open access article distributed under the terms and conditions of the Creative Commons Attribution (CC BY) license (https:/ / creativecommons.org/licenses/by/ $4.0 /)$.
School of Mechanical and Power Engineering, Harbin University of Science and Technology, Harbin 150080, China; zhaopeiyi@hrbust.edu.cn (P.Z.); zl2274548078@163.com (L.Z.)

* Correspondence: xianli.liu@hrbust.edu.cn

\begin{abstract}
Subsurface cracks in ultrasonic-vibration-assisted grinding (UVAG) of optical glasses often exhibit diverse forms and proportions. Due to the variety of loads involved in crack formation and propagation, the crack forms and propagation depths have different sensitivities to each process parameter. Predicting the maximum subsurface cracks depth (MSSCD) by considering the varying effects of process parameters plays a key role in implementing effective control of the UVAG process. In this work, the subsurface crack forms and their proportions are investigated by conducting 40 sets of UVAG experiments. The varying effects of the grinding and ultrasonic parameters on the crack form proportions are unveiled by using grey relational analysis. The weighted least square support vector machine (WLS-SVM) prediction model for the MSSCD was developed. Twelve sets of UVAG experiments were carried out to validate the proposed model. The results show that arc-shaped cracks and bifurcated cracks account for $72.5 \%$ of all cracks, while ultrasonic vibration amplitude influences most of the proportions of arc-shaped and bifurcated cracks. Compared to other widely used prediction methods, the maximum and average relative prediction errors of the proposed model are $10.54 \%$ and $5.59 \%$, respectively, which proves the high prediction accuracy of the model.
\end{abstract}

Keywords: ultrasonic-vibration-assisted grinding; optical glass; subsurface crack; crack forms; support vector machine

\section{Introduction}

Optical glasses are widely used in optical and aerospace applications. However, they are very brittle and have low fracture toughness, thus being prone to micro-cracks developing in the subsurface layers during conventional grinding processes. The maximum depth of subsurface cracks has a significant effect on the machining quality and even efficiency of the following processing [1]; thus, correct prediction of the maximum subsurface cracks depth is important for controlling the subsurface damage and overall grinding process efficiency.

UVAG has clear technical advantages in substantially reducing the average cutting force and quantity of micro-cracks [2]. However, inducing high-frequency vibrations and modifying abrasive grain motion significantly change the stresses at the contact area between the abrasive grains and the glass material compared to conventional grinding [3]. This directly affects the grinding force and dynamic impulse and the formation and propagation of subsurface cracks.

The subsurface cracks may not propagate in a single form. Furthermore, abrasive grains used on the grinding wheel are of different varieties and their shapes are random. Thus, the subsurface cracks in UVAG of the optical glasses often exhibit diverse forms and are numerous. Due to the different influencing factors of the grinding loads, the quantities and distributions of multiple cracks forms are also significantly different. This may lead to uncertainty in estimating the crack maximum propagation depth. Hence, predicting 
the maximum subsurface crack depth while considering the different effects of the process parameters is of great significance.

During the past decade, research has focused on the formation and prediction of subsurface cracks, and a number of useful results have been obtained. Fouad [4] analyzed the effects of process parameters on subsurface crack depth; the changing law of subsurface damage was also researched by changing each parameter. However, it proved hard to evaluate these effects using the adopted approach. Li [5] developed a regression model for subsurface crack depth (SSCD) estimation by combining theoretical mechanical analysis and experimental approach, but the scratching tests conducted in this work differed from the practical machining, as the abrasive grains used in the latter are often random in shape and quantity. There are also many useful studies on the prediction of SSCD by using simulations [6] and regression analysis [7]. To develop an analytical approach, Yu [8] used the damage-zone analysis method and verified the accuracy of the proposed model experimentally. To investigate the maximum subsurface crack depth (MSSCD), Lv [9] researched the critical formation conditions of MSSCD by conducting a double indentation test. Based on the mechanical analysis of indentation test results, Esmaeilzare [10] and Yao [11] analyzed the relationship between the MSSCD and surface roughness and drew a similar conclusion that the two parameters had the same trends. However, some important actual machining factors were not considered, such as the different influences of various crack forms and process parameters. Li [12] developed an analytical SSCD model based on the analysis of crack sizes and microscopic asperity (Rz). However, the crack forms considered in that work were strictly limited to the median and lateral cracks, whereas subsurface cracks often vary in both shape and size [13]. Li innovatively researched the fracture behavior and the threshold load in radial crack propagation by conducting a nanoindentation test [14]. Pansare pointed an easily visible technique for authentication of epoxy composites by using UV visible and IR light, which may provide new methods for investigating the subsurface cracks in grinding of optical glasses [15].

It can be concluded from the above literature survey that few reports provide a deeper understanding of multiple subsurface crack forms in the actual UVAG process. Since the formation of the crack with maximum depth can be different from those in scratching or indentation tests, it is necessary to investigate the distribution of multiple crack forms and their relation to the maximum depth crack. The effect of changing each parameter on the subsurface crack propagation and MSSCD is quite different. The different influences of those factors should be fully considered in the prediction of MSSCD, but only a few relevant studies are available.

In this paper, the varying effects of each grinding process parameter and the ultrasonic vibration amplitude on the subsurface crack forms and distributions were innovatively investigated using the grey relational analysis, and the strengths of all influencing factors were determined. A prediction model for the MSSCD was developed using the weighted least square support vector machine (WLS-SVM) method. To validate the prediction accuracy of the proposed model, ultrasonic-vibration-assisted grinding experiments were conducted on BK7 optical glass samples.

\section{Subsurface Crack Forms and Their Distribution in the UVAG Process}

\subsection{Experimental Setup}

In order to unveil the variety of subsurface crack forms in the actual UVAG process, 40 sets of experiments on BK7 optical glass samples were carried out on a five-axis ultrasonic vibration precision machining center (DMG Ultrasonic 70-5 Linear). The grinding wheel was a hollow diamond grinding wheel produced by Schott Diamantwerkzeuge $\mathrm{GmbH}$. Both internal and external coolant were used in the experiments. The experimental setup is shown in Figure 1. The molar composition and material properties of the BK7 optical glass are listed in Table 1. 


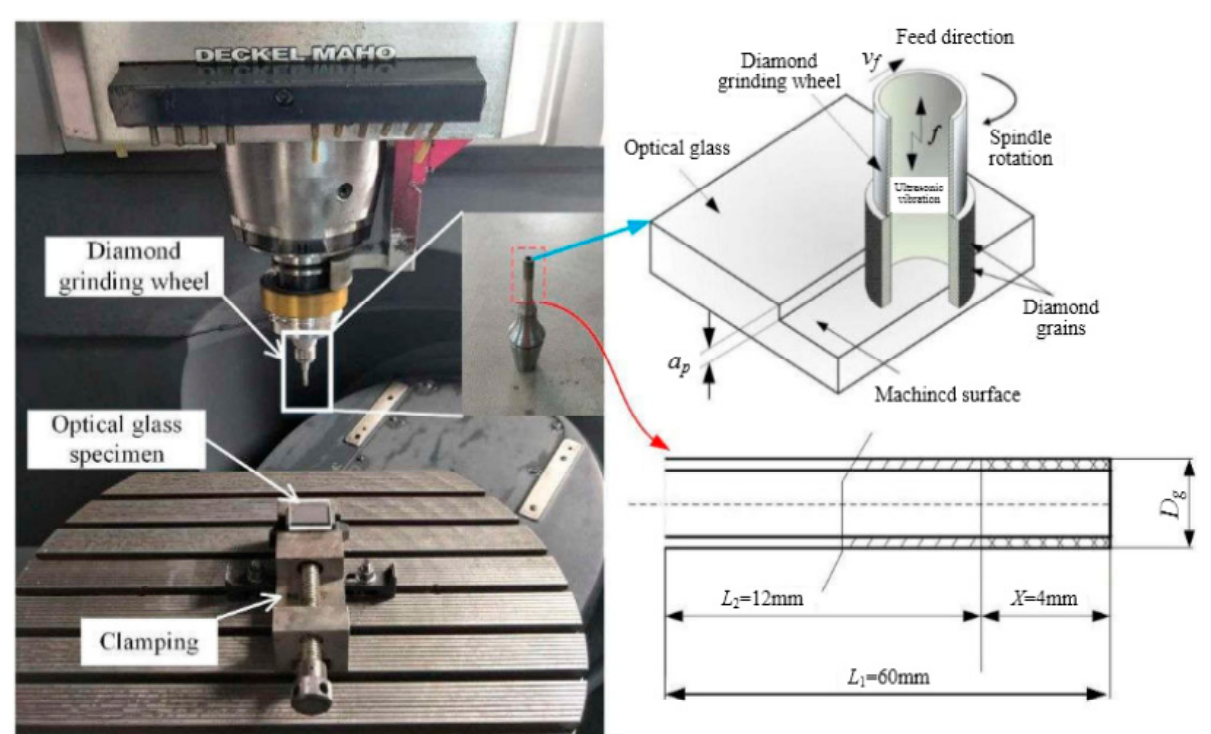

Figure 1. Experimental setup.

Table 1. Molar composition, elastic modulus, and Poisson's ratio of BK7 optical glass.

\begin{tabular}{cccccccc}
\hline Optical Glass & $\begin{array}{c}\mathrm{SiO}_{2} \\
(\%)\end{array}$ & $\begin{array}{c}\mathrm{B}_{2} \mathrm{O}_{3} \\
(\%)\end{array}$ & $\begin{array}{c}\mathrm{Na}_{2} \mathrm{O} \\
(\mathbf{\%})\end{array}$ & $\begin{array}{c}\mathrm{K}_{2} \mathrm{O} \\
(\%)\end{array}$ & $\begin{array}{c}\mathrm{BaO} \\
(\%)\end{array}$ & $\begin{array}{c}\text { Elastic Modulus } \\
(\text { E/Gpa) }\end{array}$ & Poisson Ratio (v) \\
\hline $\mathrm{BK} 7$ & 74 & 10 & 10 & 5 & 1 & 80.9 & 0.21 \\
\hline
\end{tabular}

In order to comprehensively investigate the varying effects of process parameters on the subsurface crack quantity distribution and MSSCD, a single-factor experiment design was used in this study. The diameter of the grinding wheel $\left(D_{g}\right)$, average diameter of abrasive grains $\left(d_{a}\right)$, spindle rotational speed $(n)$, feed rate $\left(V_{f}\right)$, grinding depth $\left(a_{p}\right)$, and ultrasonic vibration amplitude $(A)$ were selected as the key experimental process parameters. Supplementary Materials Table S1 summarizes the grinding and ultrasonic vibration process specifications used in the experiments. After experiment completion, the cross-sections of specimens were ultra-precision polished, followed by hydrofluoric acid etching. In order to prevent excessive crack corrosion, hydrofluoric acid (40\%) was diluted to $1 \%$, and the polished specimens were submerged in the diluted hydrofluoric acid solution for $10 \mathrm{~min}$. The polishing method and the subsurface crack morphologies after corroding are shown in Figure 2.

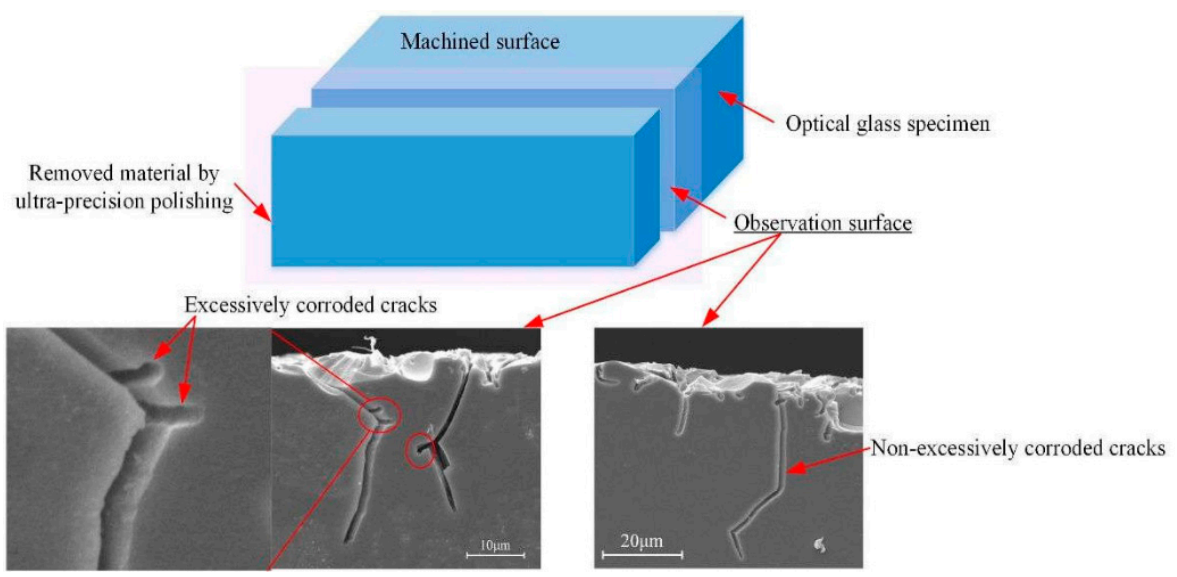

Figure 2. Subsurface cracks with different corrosion extents. 
After the polishing and corroding, the optical glass specimens were cleaned several times by using an ultrasonic vibration cleaner. A scanning electron microscope was used to examine the morphologies of the subsurface cracks. By scanning all over the crosssection of each sample, the sub-surface crack with maximum depth along grinding depth direction was found using ImageJ software. The highest and lowest points were selected at the top of the machined surface and the bottom of propagation position of the crack, respectively. Then, the value of MSSCD was obtained using the software. An example of profile measurement is shown in Figure 3.

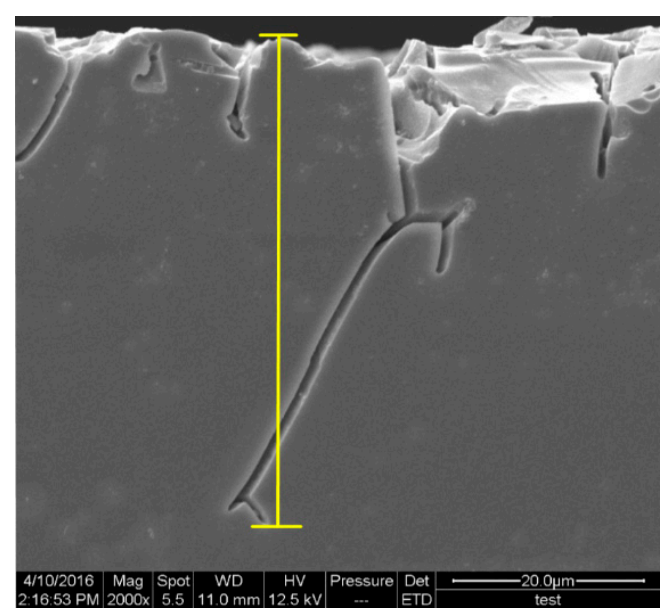

Figure 3. Profile measurement for subsurface crack depth determination.

\subsection{Variety of Subsurface Crack Forms and Their Proportions}

Figure 4 shows the observed subsurface cracks with various shapes and sizes appearing on the cross-section surface (observed surface). Among them, three typical subsurface crack forms (i.e., arc-shaped, bifurcated, and straight median and lateral cracks) can be distinguished, and a few cracks with irregular shapes (other cracks) can also be found. By examining the entire cross-section surface, it is observed that the cracks of the three typical forms constitute a significant proportion of all subsurface cracks.

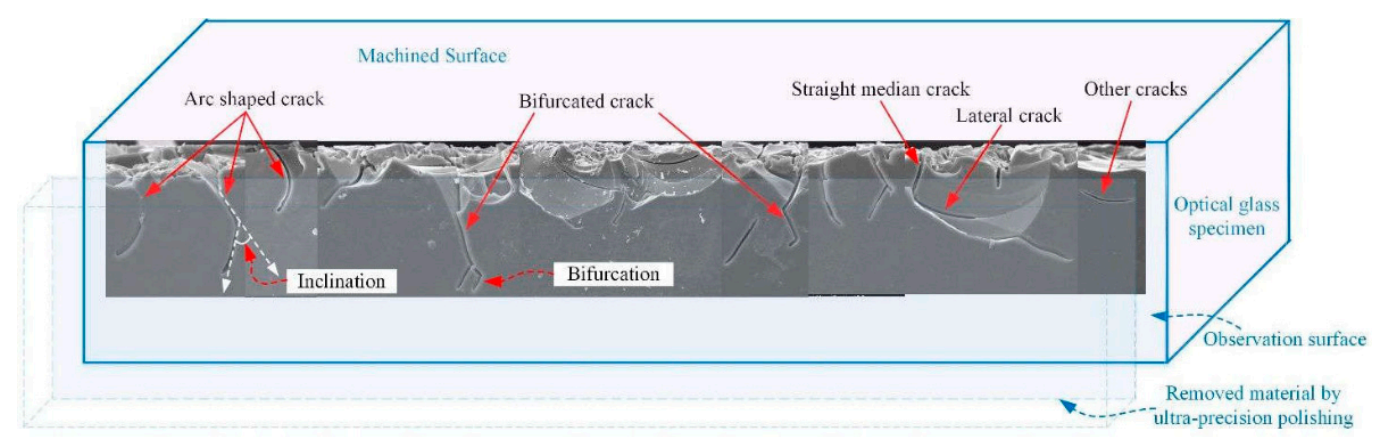

Figure 4. Subsurface cracks observed in experiments.

In order to further investigate the proportion of each crack form, the crack propagation depths were examined by an image measurement software. To filter out cracks of small depth, a threshold must be selected. In ultrasonic-vibration-assisted grinding of optical glasses, the subsurface cracks with maximum propagation depth always originated from median cracks, which means that the lateral cracks do not have a significant effect on the subsurface damage. According to the previous studies [16,17], the ratio between the propagation depth of lateral and median subsurface cracks is in the range 0.2-0.3; thus, the threshold value adopted in this work $\left(h_{c}\right)$ was as follows:

$$
h_{c}=0.2 \times M S S C D_{i}
$$


where $\operatorname{MSSCD}_{i}(i=1,2, \ldots, 40)$ is the maximum subsurface depth of all the cracks in $i$ th experiment.

By using the above measuring method, the propagation depths of all selected cracks were obtained; thus, the proportions of the three typical subsurface cracks and other cracks were determined, as shown in Figure 5.

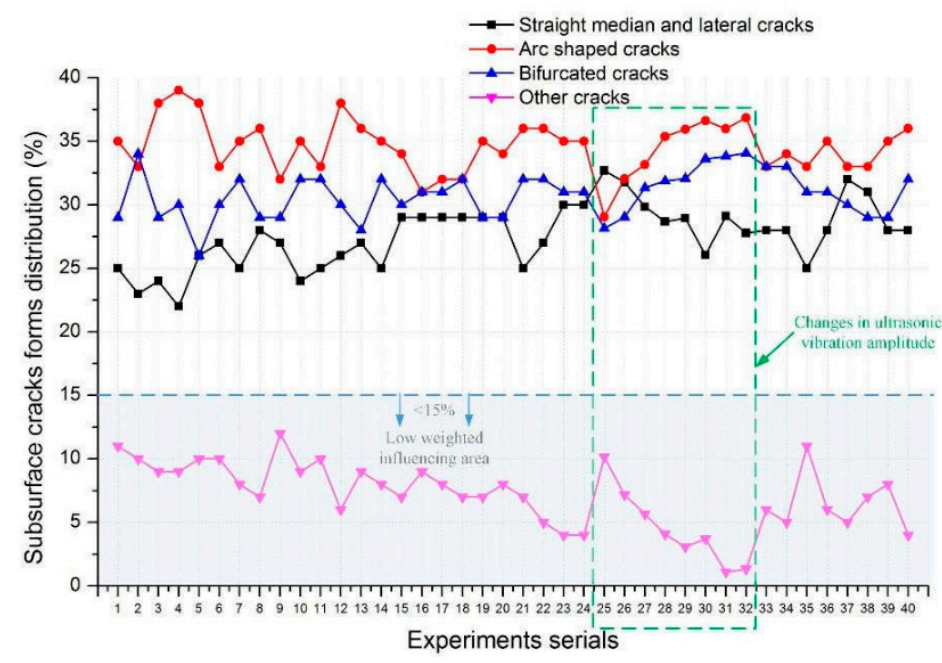

Figure 5. Proportions of subsurface cracks.

According to the statistics of the number of subsurface cracks obtained from 40 groups of experiments, the average number of linear and lateral cracks in each group is about 3000 , the average number of arc cracks is about 4000 , and the average number of bifurcation cracks is about 3600 . The average number of other cracks is about 750 .

From Figure 5, the proportion of the three typical subsurface cracks is over $85 \%$ of the total, which means the subsurface cracks in the 40 experiments are mainly straight median and lateral, arc-shaped, and bifurcation cracks. The proportion of other cracks is the smallest, while that of the arc-shaped cracks is the biggest. The average proportions of arc-shaped, bifurcation, and straight median cracks in the 40 experimental sets are $34.5 \%$, $30.6 \%$, and $27.4 \%$, respectively. This means that more than $70 \%$ of the cracks did not follow the standard paths of median and lateral cracks. It can also be seen from Figure 5 that with the change in the ultrasonic vibration amplitude, the proportions of arc-shaped and bifurcated cracks increased, while those of the straight median and lateral cracks and other cracks decreased.

By examining the morphologies of all the maximum depth cracks in the 40 sets of experiments, a summary of maximum-depth subsurface crack form distribution was obtained, as shown in Table 2.

Table 2. Proportion of cracks with maximum depth.

\begin{tabular}{ccccc}
\hline & $\begin{array}{c}\text { Arc-Shaped } \\
\text { Cracks }\end{array}$ & $\begin{array}{c}\text { Bifurcation } \\
\text { Cracks }\end{array}$ & $\begin{array}{c}\text { Straight Median } \\
\text { and Lateral Cracks }\end{array}$ & Other Cracks \\
\hline $\begin{array}{c}\text { Times of the maximum } \\
\text { depth cracks }\end{array}$ & 17 & 12 & 9 & 2 \\
\hline
\end{tabular}

It is clear from Table 2 that in the 40 sets of UVAG of optical glass experiments, almost $78 \%(31 / 40)$ of the subsurface cracks with maximum propagation depth were not straight median cracks, which means the cracks with maximum depth were more likely to evolve from the arc-shaped and bifurcated cracks. 


\subsection{Grey Relevance Based Sensitivity of Subsurface Crack Proportions to Process Parameters}

In order to unveil the major and minor effects of process parameters on the distribution of subsurface cracks and MSSCD, the well-known grey relational analysis method [18] was used in the present work. The grey relevance between process parameters and proportions of subsurface crack forms, $\gamma\left(A_{i}, B_{i}\right)$, can be expressed as follows:

$$
\gamma\left(A_{i}, B_{i}\right)=\left\{\begin{array}{c}
\frac{1+\left|\delta\left(A_{i}\right)\right|}{1+\left|\delta\left(A_{i}\right)\right|+\left|\xi\left(A_{i} / B_{i}\right)\right|}, \overline{K_{A B}} \geq 0 \\
-\frac{1+\left|\delta\left(A_{i}\right)\right|}{1+\left|\delta\left(A_{i}\right)\right|+\mid \xi\left(A_{i} / B_{i}\right)}, \overline{K_{A B}}<0
\end{array}\right.
$$

where $A_{i}$ is the $i$ th parameter, $B_{i}$ is the proportion of the $i$ th subsurface crack form, and $\delta\left(A_{i}\right)$ is the coefficient of variation of sequence $K_{A i}$.

Using Equation (2), the relevance of each parameter to the crack forms distribution was calculated, and the results are shown in Figure 6.

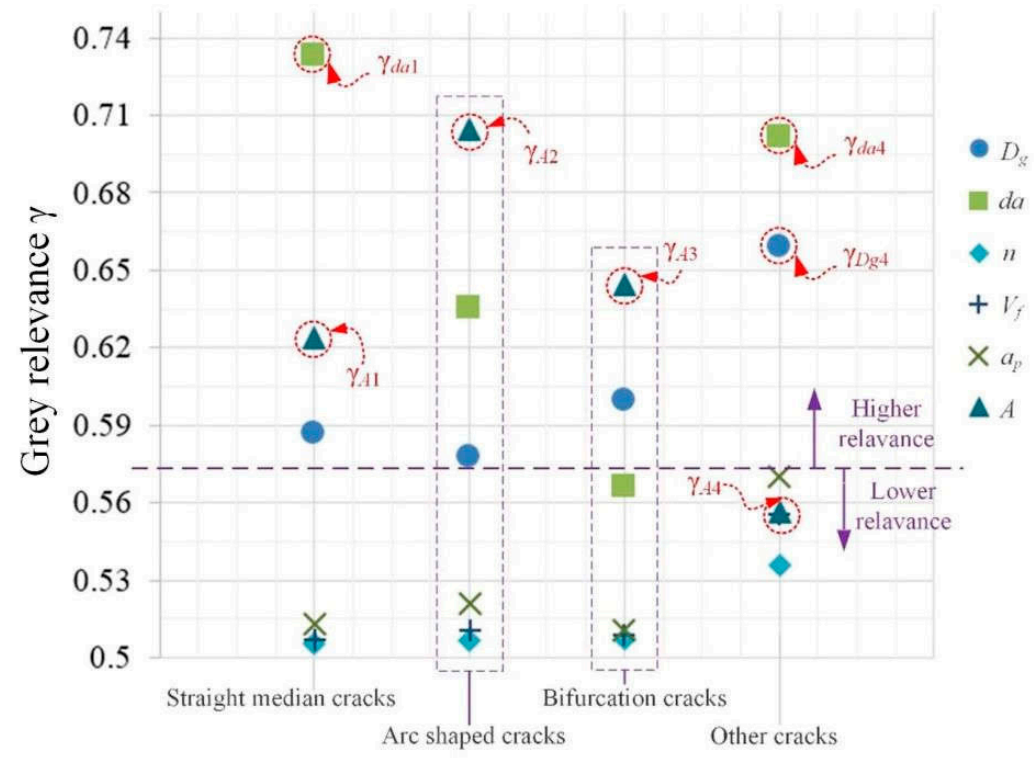

Figure 6. Relevance of process parameters to subsurface crack form distribution.

From Figure 6, it can be seen that the relevance of all parameters to the distribution of subsurface crack forms is over 0.5 , and among them, the diameter of grinding wheel $\left(D_{g}\right)$, average diameter of abrasive grains $\left(d_{a}\right)$, and ultrasonic vibration amplitude $(A)$ have higher relevance, whereas the spindle rotation speed $(n)$, feed rate $\left(V_{f}\right)$, and grinding depth $\left(a_{p}\right)$ have lower relevance.

It can also be seen from Figure 6 that the changes in the diameter of grinding wheel and average diameter of abrasive grains both have obvious effects on the proportion of other cracks $\left(\gamma_{d a 4}\right.$ and $\left.\gamma_{D g 4}\right)$, whereas the changes in the grinding parameters and ultrasonic vibration amplitude do not have a significant effect.

Furthermore, the relevance of ultrasonic vibration amplitude to the proportion of the arc-shaped, bifurcated, and straight median crack forms is over 0.6. In grey relational analysis algorithm, the bigger the correlation is, the closer the relationship between process parameter and cracks proportion is; when the correlation is 1, the process parameter and cracks proportion would be absolutely relative. In the present work, a threshold of 0.6 was used to determine the sensitivity of subsurface crack proportions to process parameters. Thus, changing the ultrasonic vibration amplitude is more influential to the proportion of these three types of cracks, especially arc-shaped $\left(\gamma_{A 2}\right)$ and bifurcation cracks $\left(\gamma_{A 3}\right)$. The main reason for this is that the inclination and bifurcation of subsurface cracks are mainly influenced by the relative shear effects and the impulse forces of abrasive grains; among them, the relative shear effects were originated from the dynamic movement of abrasive grains [12,19], and the 
impulse force, i.e., the maximum impact force between abrasive grains and optical glass workpiece $\left(F_{m}\right)$ during one vibration cycle, can be expressed as follows [20]:

$$
\begin{gathered}
\text { Impulse }=\int_{\text {cycle }} F_{m} d t \\
\left\{\begin{array}{l}
F_{m}=\frac{F}{\Delta t \cdot f} \\
w=\left(\frac{F}{2 \tan \beta \sqrt{\tan ^{2} \beta+2}[(1 / 2)-(1 / \pi) \arcsin (1-(w / A))] H_{V} N_{a}}\right)^{\frac{1}{2}}
\end{array}\right.
\end{gathered}
$$

In the present work, the parameters related to material properties remained unchanged, and the semi-angle ( $\beta$, whose meaning is illustrated in Figure 7$)$ between two opposite edges of an abrasive particle remained unchanged. Equation (4) can then be simplified as follows:

$$
F \propto w^{2} \cdot \sqrt{\arcsin \left(1-\frac{w}{A}\right)}
$$

where $A$ is the ultrasonic vibration amplitude, and $w$ is the maximum depth of abrasive grain penetration into the optical glass specimen.
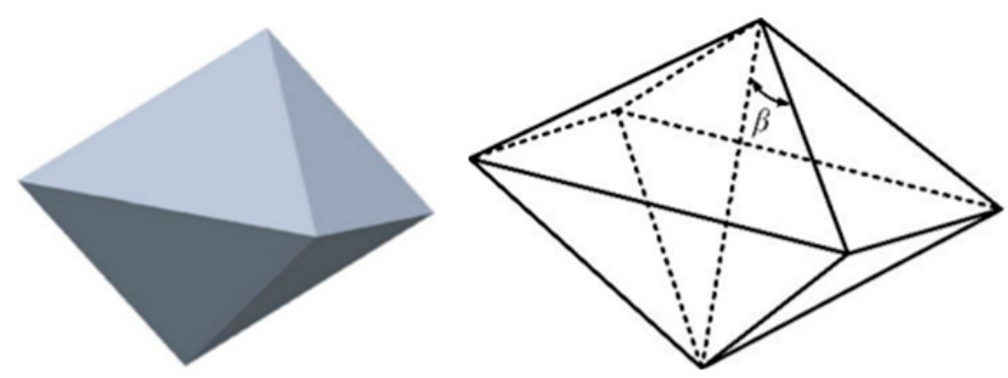

Figure 7. Semi-angle between two opposite edges of abrasive grain.

From Equations (3) and (5), it can be seen that the impulse of an abrasive grain is mainly affected by the penetration depth $(w)$ and ultrasonic vibration amplitude $(A)$, which means that changing grinding parameters $n, V_{f}$, or $a_{p}$ will not have an obvious effect on the distribution of arc-shaped and bifurcated cracks. Thus the ultrasonic vibration amplitude has the highest impact on the changes in the proportion of arc-shaped and bifurcated cracks.

\subsection{Determination of the Strength of Influence of Process Parameters}

Since the varying effects of process parameters on the proportion of subsurface cracks are caused by the changes in each parameter, the strength of influence should thus be determined for each process parameter.

The arc-shaped cracks and bifurcated cracks comprise a high percentage of all the subsurface cracks ( $72.5 \%$ in the present work); the relevance of each parameter to these two crack forms is taken as primary basis for the influence strength determination. To clearly identify the parameters and subsurface crack forms during the influence strength determination, the relevance of the process parameters to subsurface crack forms indicated in Figure 3 can be quantified as shown in Table 3. 
Table 3. Influence strength names and grey relevance of process parameters to subsurface crack forms.

\begin{tabular}{cccccc}
\hline Weights & $\begin{array}{c}\text { Processing } \\
\text { Parameters }\end{array}$ & $\begin{array}{c}\text { Straight Median } \\
\text { Cracks }\end{array}$ & $\begin{array}{c}\text { Arc-Shaped } \\
\text { Cracks }\end{array}$ & $\begin{array}{c}\text { Bifurcation } \\
\text { Cracks }\end{array}$ & Other Cracks \\
\hline$\eta_{1}$ & $D_{g}$ & $\gamma_{11}$ & $\gamma_{12}$ & $\gamma_{13}$ & $\gamma_{14}$ \\
$\eta_{2}$ & $d_{a}$ & $\gamma_{21}$ & $\gamma_{22}$ & $\gamma_{23}$ & $\gamma_{24}$ \\
$\eta_{3}$ & $n$ & $\gamma_{31}$ & $\gamma_{32}$ & $\gamma_{33}$ & $\gamma_{34}$ \\
$\eta_{4}$ & $V_{f}$ & $\gamma_{41}$ & $\gamma_{42}$ & $\gamma_{43}$ & $\gamma_{44}$ \\
$\eta_{5}$ & $a_{p}$ & $\gamma_{51}$ & $\gamma_{52}$ & $\gamma_{53}$ & $\gamma_{54}$ \\
$\eta_{6}$ & $A$ & $\gamma_{61}$ & $\gamma_{62}$ & $\gamma_{63}$ & $\gamma_{64}$ \\
\hline
\end{tabular}

The relevance of each process parameter to arc-shaped, bifurcation, and other cracks can be summarized as follows:

$$
\Gamma=\left\{\gamma_{1 i}, \gamma_{2 i}, \gamma_{3 i}, \gamma_{4 i}, \gamma_{5 i}, \gamma_{6 i}\right\}, i=1,2,3,4
$$

The normalized relevance of Equation (6) can be written as follows:

$$
\Gamma^{\prime}=\left\{\gamma_{1 i}^{\prime}, \gamma_{2 i}^{\prime}, \gamma_{3 i}^{\prime}, \gamma_{4 i}^{\prime}, \gamma_{5 i}^{\prime}, \gamma_{6 i}^{\prime}\right\}, i=1,2,3,4
$$

According to Figure 5, the subsurface cracks are mainly the straight median, arcshaped, and bifurcation cracks. Among them, the cracks with maximum depths originated mostly from the latter two types. Thus, the relevance of each process parameter to the arc-shaped and bifurcation cracks should be fully considered, whereas those of other cracks can be ignored while determining the influence strengths. The influence strength of each parameter was obtained from Equation (8), and the results are listed in Table 4.

$$
\eta_{j}=\frac{\gamma_{j 2}^{\prime}+\gamma_{j 3}^{\prime}-\gamma_{j 4}^{\prime}}{\sum_{k=1}^{6} \gamma_{k 2}^{\prime}+\sum_{k=1}^{6} \gamma_{k 3}^{\prime}}, j=1,2,3,4,5,6
$$

Table 4. Strength of influence of process parameters.

\begin{tabular}{ccccccc}
\hline Parameters & $\boldsymbol{D}_{\boldsymbol{g}}$ & $\boldsymbol{d}_{\boldsymbol{a}}$ & $\boldsymbol{n}$ & $\boldsymbol{V}_{\boldsymbol{f}}$ & $\boldsymbol{a}_{\boldsymbol{p}}$ & $\boldsymbol{A}$ \\
\hline Weights & $\eta_{1}$ & $\eta_{2}$ & $\eta_{3}$ & $\eta_{4}$ & $\eta_{5}$ & $\eta_{6}$ \\
Values & 0.166 & 0.185 & 0.213 & 0.144 & 0.145 & 0.147 \\
\hline
\end{tabular}

\section{Prediction of MSSCD in UVAG of BK7 Optical Glass}

\section{Modeling of MSSCD in UVAG of BK7 Optical Glass Using WLS-SVM}

In the present work, the training data can be denoted as:

$$
D=\left\{\left(x^{(n)}, \operatorname{MSSCD}_{n}\right)\right\}, x^{(n)} \in R^{n}, \operatorname{MSSCD}_{n} \in R
$$

where $x^{(n)}$ represents the experimental parameters, and $M S S C D_{n}$ represents the experimental measurements of maximum subsurface crack depths.

The prediction model for the MSSCD can be expressed as follows:

$$
\operatorname{MSSCD}^{*}(x)=\omega \cdot \varphi(x)+b
$$

where $\omega$ represents the dimension of feature space, $b$ is the offset coefficient, and $\varphi(x)$ is a non-linear mapping function from the feature space $R^{n}$ to a higher-dimensional space $R^{m}$. 
If the error between the predicted MSSCD and its actual measurement is represented by $\varepsilon$, the problem of accurately predicting $M S S C D$ can be re-written as minimization of the error as follows:

$$
\begin{aligned}
& \min \frac{1}{2}\|\omega\|^{2}+C \sum_{i=1}^{n}\left(\zeta_{i}+\zeta_{i}^{*}\right) \\
& \text { s.t. }\left\{\begin{array}{c}
\eta \cdot \varphi\left(x_{i}\right)+b-M S S C D_{i} \leq \zeta_{i}+\varepsilon \\
M S S C D_{i}-\eta \cdot \varphi\left(x_{i}\right)-b \leq \zeta_{i}^{*}+\varepsilon \\
\zeta_{i}, \zeta_{i}^{*} \geq 0
\end{array}\right\}
\end{aligned}
$$

where $C$ is the penalty coefficient, and $\zeta_{i}$ and $\zeta_{i}{ }^{*}$, are the relax variables [21].

The dual form [21] of Equation (11) can be obtained by using a Lagrange function [21] and the KKT theorem [22]:

$$
\begin{aligned}
& \max \left[-\frac{1}{2} \sum_{i, j=1}^{n}\left(\alpha_{i}-\alpha_{i}^{*}\right)\left(\alpha_{j}-\alpha_{j}^{*}\right) k\left(x_{i}, x_{j}\right)+\sum_{i=1}^{n}\left(\alpha_{i}-\alpha_{i}^{*}\right) \operatorname{MSSCD} i-\varepsilon \sum_{i=1}^{n}\left(\alpha_{i}+\alpha_{i}^{*}\right)\right] \\
& \text { s.t. }\left\{\begin{array}{c}
\sum_{i=1}^{l}\left(\alpha_{i}-\alpha_{i}^{*}\right)=0 \\
0 \leq \alpha_{i}, \alpha_{i}^{*} \leq c
\end{array}\right\}
\end{aligned}
$$

where $k\left(x_{i}, x_{j}\right)$ is the covariance function, and the MSSCD prediction can be expressed as follows:

$$
\operatorname{MSSCD}^{*}(x)=\sum_{x \in S V}\left(\alpha_{i}-\alpha_{i}^{*}\right) k\left(x_{i}, x\right)+b
$$

Due to the varying effects of each parameter on both the MSSCD and the proportion of subsurface crack forms, these effects should be considered by using the influence strengths listed in Table 4. Equation (11) thus becomes:

$$
\min \frac{1}{2}\|\omega\|^{2}+C \sum_{i=1}^{n} \eta_{i}\left(\zeta_{i}+\zeta_{i}^{*}\right)
$$

where $\eta_{i}$ is the influence strength of each class of experimental parameters as indicated in Table 4.

A Gaussian kernel function was used in the present work because of its good smoothness and symmetry:

$$
k\left(x, x_{i}\right)=\exp \left(\frac{-\left\|x-x_{i}\right\|^{2}}{\sigma^{2}}\right)
$$

where $x_{i}$ is the center position of the $i$ th radial basis function, and $\sigma$ is the kernel function parameter indicating the function width.

In order to determine the penalty coefficient $(C)$ and kernel function parameter $(\sigma)$, cross-validation method was used before the prediction, and training data sets shown in Supplementary Materials Table S1 were used to optimize the above two parameters, Python was adopted for model implementation, the order of cross-validation was 6, and the optimized $C$ and $\sigma$ values were 64 and 0.2588 , respectively.

\section{Validation of Proposed Model}

To validate the proposed model, 12 groups of ultrasonic-vibration-assisted grinding experiments on BK7 optical glass samples were carried out. The experimental specifications are shown in Table 5 . In order to comprehensively validate the prediction accuracy of the proposed model, the least square support vector machine (LS-SVM) and Gaussian process regression (GPR) method were both used to develop the prediction model for the MSSCD. The prediction results are shown in Figure 8. 
Table 5. Experimental grinding and ultrasonic vibration parameters.

\begin{tabular}{ccccccc}
\hline Serial Number & $D_{g}(\mathbf{m m})$ & $d_{a}(\mu \mathrm{m})$ & $N(\mathbf{r} / \mathbf{m i n})$ & $V_{f}(\mathbf{m m} / \mathbf{m i n})$ & $a_{p}(\mu \mathrm{m})$ & $\mathrm{A}(\mu \mathrm{m})$ \\
\hline 1 & 4 & 76 & 11,000 & 110 & 50 & 5 \\
2 & 4 & 64 & 13,000 & 110 & 70 & 6 \\
3 & 6 & 76 & 15,000 & 110 & 50 & 7 \\
4 & 4 & 76 & 11,000 & 100 & 60 & 7 \\
5 & 4 & 64 & 11,000 & 120 & 60 & 7 \\
6 & 4 & 91 & 8000 & 110 & 60 & 7 \\
7 & 2 & 91 & 11,000 & 160 & 60 & 7 \\
8 & 4 & 76 & 11,000 & 110 & 100 & 7 \\
9 & 6 & 46 & 11,000 & 110 & 120 & 7 \\
10 & 4 & 76 & 11,000 & 110 & 140 & 7 \\
11 & 8 & 46 & 1500 & 110 & 60 & 7 \\
12 & 4 & 64 & 2000 & 110 & 60 & 7 \\
\hline
\end{tabular}

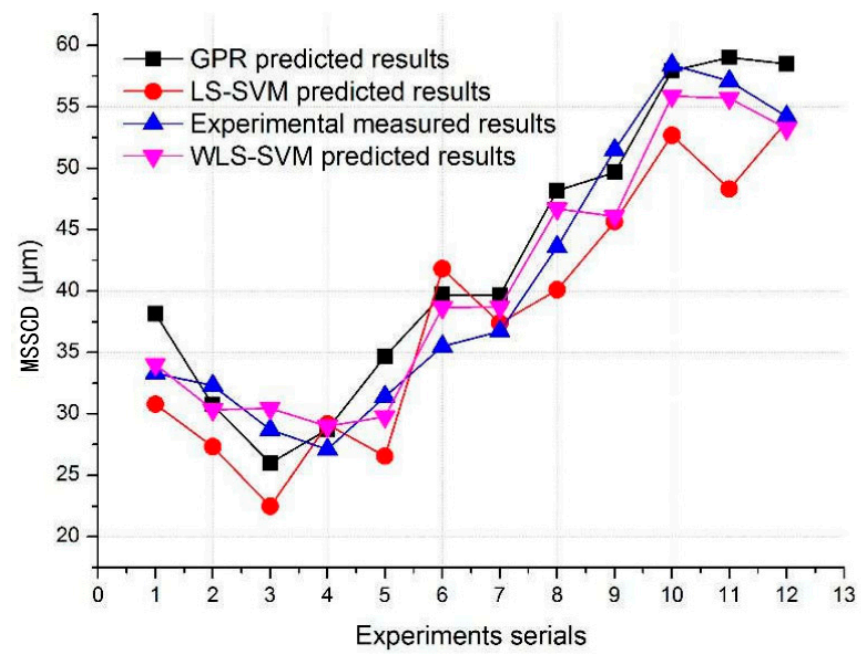

Figure 8. Comparison between WLS-SVM, LS-SVM, and GPR predictions and experimental results.

To evaluate the accuracy of the model, it is necessary to calculate the error between the predicted and experimental results, which can be defined as follows:

$$
E_{c} \%=\left|\left(S S D^{*}-S S D\right) / S S D\right| \times 100
$$

The average relative error $\left(E_{A c}\right)$ of prediction results can be expressed as follows:

$$
E_{\mathrm{Ac}} \%=\frac{1}{n} \sum_{1}^{n} E_{\mathcal{C}}
$$

From Figure 8, it can be seen that all three types of prediction results have a similar trend as the experimentally measured values. Among them, 75\% of LS-SVM predicted results are smaller than measured results, and $67 \%$ of GPR-based prediction results are bigger than the experimental results. That is, the LS-SVM and GPR models cannot match the experimental training data well, which causes most of the predicted results to deviate to one side. It can be easily seen from Figure 8 that half of the WLS-SVM prediction results are bigger than experimental results, which means all the WLS-SVM predicted results are evenly distributed about the actual measurement data.

Table 6 shows the specific relative errors calculated by Equations (16) and (17). It can be seen from Table 6 that the LS-SVM method without weighting factors has the biggest maximum relative error $(21.72 \%$, validation experiment 11$)$, while that of the proposed model is the smallest (10.54\%). This is likely because the essence of LS-SVM is to solve the convex quadratic programming problem and obtain its optimal global solution; the 
LS-SVM and GPR method both are well adapted to solve the problems of small sample data: non-linearity. However, when isolated nodes exist in training data which were caused by the differential influences of training input data on the output data, the prediction accuracy would decrease. Another possible reason is the spindle rotation speed in validation experiment 11 differed significantly from the other experiments, i.e., the diameter of grinding wheel and average diameter of abrasive grains in validation experiment 11 were both the largest of all. Since any combination of process parameters is treated as coordinates in a high dimensional space, the LS-SVM model could not accurately fit the three extreme values of coordinates. According to the influence strengths listed in Table 4, the influence strength of spindle rotation speed is the smallest; thus, the proposed improved WLS-SVM model could reduce the disturbance of this process parameter combination.

Table 6. Errors between predicted and experimental results.

\begin{tabular}{cccc}
\hline & $\begin{array}{c}\text { Maximum Relative } \\
\text { Error }\end{array}$ & $\begin{array}{c}\text { Minimum Relative } \\
\text { Error }\end{array}$ & $\begin{array}{c}\text { Average Relative } \\
\text { Error }\end{array}$ \\
\hline GPR method & $14.56 \%$ & $0.8 \%$ & $7.61 \%$ \\
LS-SVM method & $21.72 \%$ & $0.7 \%$ & $11.07 \%$ \\
WLS-SVM method & $10.54 \%$ & $1.8 \%$ & $5.59 \%$ \\
\hline
\end{tabular}

Furthermore, the proposed model has the smallest average relative error (5.59\%). A plausible reason for this is that the proposed model can better account for the different effects of the six process parameters and can fit the experimental validation data more accurately. The minimum relative error of the proposed model is the largest $(1.8 \%)$ but is still considered acceptable. The predicted MSSCD values are in good agreement with the experimental results, which proves the high prediction accuracy of the proposed model.

\section{Conclusions}

In this paper, a WLS-SVM predicting model for the MSSCD in UVAG of optical glass is presented. A focus is on the systematic understanding of the influence of multiple process parameters on the proportion of subsurface crack forms from carefully designed experiments. The following conclusions can be drawn from this study:

(1) The experimental results for UVAG of optical glass show that the subsurface crack forms are dominated by arc-shaped, bifurcated, and straight median cracks. The crack with the maximum propagation depth had the probability of $72.5 \%(29 / 40)$ in this work to be an arc-shaped or bifurcation crack.

(2) The relational analysis results demonstrate that the proportions of arc-shaped and bifurcated cracks are most sensitive to the ultrasonic vibration amplitude, for which the intrinsic reason is the impulse on the cracks exerted by the downward vibration of abrasive grains. The proportions of straight median and other cracks are most sensitive to the average diameter of abrasive grains, whereas the other grinding process parameters are relatively noninfluential to the crack proportion.

(3) The comparison of prediction and experimental results shows that the maximum error of the developed WLS-SVM prediction model is $10.54 \%$, which is smaller than that of the other two widely used methods (LS-SVM and GPR), while the relative error is $5.59 \%$, which demonstrates its high prediction accuracy.

Supplementary Materials: The following are available online at https:/ / www.mdpi.com/article/10 .3390/app11167553/s1, Table S1: Experimental grinding and ultrasonic vibration parameters.

Author Contributions: Writing-original draft preparation, L.Z.; writing-review and editing, P.Z.; Conceptualization, X.L. All authors have read and agreed to the published version of the manuscript.

Funding: This research was funded by National Natural Science Foundation of China, grant number 51875145 . 
Institutional Review Board Statement: Not applicable.

Informed Consent Statement: Not applicable.

Data Availability Statement: Not applicable.

Conflicts of Interest: The authors declared no potential conflict of interest with respect to the research, authorship, and/or publication of this article.

$\begin{array}{ll}\text { Abbreviations } \\ \text { GPR } & \text { Gaussian process regression } \\ \text { LS-SVM } & \text { Least square supporting vector machine } \\ \text { MSSCD } & \text { Maximum subsurface cracks depth } \\ \text { UVAG } & \text { Ultrasonic-vibration-assisted grinding } \\ \text { WLS-SVM } & \text { Weighted least square supporting vector machine }\end{array}$

\section{References}

1. Bi, G.; Xu, T.L.; Peng, Y.F.; Guo, X.Q. Feature Extraction of Acoustic Emission Signal for Diamond Scratching of Optical Glass BK7. Opt. Precis. Eng. 2017, 25, 402-410.

2. Zhao, P.Y.; Zhou, M.; Liu, X.L.; Jiang, B. Effect to the Surface Composition in Ultrasonic Vibration-Assisted Grinding of BK7 Optical Glass. Appl. Sci. 2020, 10, 516. [CrossRef]

3. Baraheni, M.; Amini, S. Predicting subsurface damage in silicon nitride ceramics subjected to rotary ultrasonic assisted face grinding. Ceram. Int. 2019, 45, 10086-10096. [CrossRef]

4. Lakhdari, F.; Bouzid, D.; Belkhir, N.; Herold, V. Surface and subsurface damage in Zerodur®glass ceramic during ultrasonic assisted grinding. Int. J. Adv. Manuf. Technol. 2016, 90, 1993-2000. [CrossRef]

5. Li, S.; Wang, Z.; Wu, Y. Relationship between subsurface damage and surface roughness of optical materials in grinding and lapping processes. J. Mater. Process. Technol. 2008, 205, 34-41. [CrossRef]

6. Pashmforoush, F.; Esmaeilzare, A. Experimentally validated finite element analysis for evaluating subsurface damage depth in glass grinding using Johnson-Holmquist model. Int. J. Precis. Eng. Manuf. 2017, 18, 1841-1847. [CrossRef]

7. Zhang, F.H.; Li, C.; Zhao, H.; Leng, B. Prediction model and experimental study of subsurface damage depths in grinding for K9 glasses. China Mech. Eng. 2016, 27, 2442-2446.

8. Yu, D.P.; Wong, Y.S.; Hong, G.S. A novel method for determination of the subsurface damage depth in diamond turning of brittle materials. Int. J. Mach. Tool Manuf. 2011, 51, 918-927. [CrossRef]

9. Lv, D.X. High Frequency Vibration Effects in Rotary Ultrasonic Machining Hard-brittle Material. Ph.D. Thesis, Harbin Institute of Technology, Harbin, China, 2014.

10. Esmaeilzare, A.; Rahimi, A.; Rezaei, S.M. Investigation of subsurface damages and surface roughness in grinding process of Zerodur glass-ceramic. Appl. Surf. Sci. 2014, 313, 67-75. [CrossRef]

11. Yao, Z.; Gu, W.; Li, K. Relationship between surface roughness and subsurface crack depth during grinding of optical glass BK7. J. Mater. Process. Technol. 2012, 212, 969-976. [CrossRef]

12. Li, H.; Yu, T.B.; Da Zhu, L.; Wang, W.S. Evaluation of grinding-induced subsurface damage in optical glass BK7. J. Mater. Process. Technol. 2016, 229, 785-794. [CrossRef]

13. Zhao, P.; Zhou, M.; Huang, S. Sub-surface crack formation in ultrasonic vibration-assisted grinding of BK7 optical glass. Int. J. Adv. Manuf. Technol. 2017, 93, 1685-1697. [CrossRef]

14. Li, X.; Jiang, L.; Mohagheghian, I.; Dear, J.P.; Li, L.; Yan, Y. New insights into nanoindentation crack initiation in ion-exchanged sodium aluminosilicate glass. J. Am. Ceram. Soc. 2018, 101, 2930-2940. [CrossRef]

15. Pansare, A.V.; Khairkar, S.R.; Shedge, A.A.; Chhatre, S.Y.; Patil, V.R.; Nagarkar, A.A. In Situ Nanoparticle Embedding for Authentication of Epoxy Composites. Adv. Mater. 2018, 30, e1801523. [CrossRef] [PubMed]

16. Diao, D.F.; Kato, K.; Hokkirigawa, K. Fracture Mechanisms of Ceramic Coatings in Indentation. J. Tribol. 1994, 116, 860-869. [CrossRef]

17. Tanja, L. Indentation Crack Profiles in Silicon Nitride. J. Eur. Ceram. Soc. 2001, 21, 211-218.

18. Yang, L.; Hao, Y.P.; Li, W.G.; Li, Z.T.; Dai, D.; Li, L.C.; Luo, B.; Zu, G.H. Relationships Among Transmission Line Icing, Conductor Temperature and Local Meteorology Using Grey Relational Analysis. High Volt. Eng. 2010, 36, 775-781.

19. Lawn, B.R. Fracture of Brittle Solids, 2nd ed.; Cambridge University: Cambridge, UK, 1993.

20. Liu, D.; Cong, W.; Pei, Z.; Tang, Y. A cutting force model for rotary ultrasonic machining of brittle materials. Int. J. Mach. Tools Manuf. 2012, 52, 77-84. [CrossRef]

21. Suykens, J.A.K.; Vandewalle, J. Least Squares Support Vector Machine Classifiers. Neural Process. Lett. 1999, 9, 293-300. [CrossRef]

22. Zhu, S.K.; Li, S.J.; Teo, K.L. Second-order Karush-Kuhn-Tucker optimality conditions for set-valued optimization. J. Glob. Optim. 2014, 58, 673-692. [CrossRef] 